\title{
SHORT-RANGE RADAR IMPLEMENTED WITH ULTRASOUND SENSOR AND PSoC5LP
}

\author{
JULIÁN R. CAMARGO L., OSCAR FLÓREZ-CEDIEL \& ORLANDO GARCÍA-HURTADO \\ Engineering Faculty, Universidad Distrital Francisco José de Caldas, Bogotá, Colombia
}

\begin{abstract}
This document presents the design and construction of a short-range radar (up to 4 meters) making use of an ultrasound sensor with which it performs a constant 2D scan of the environment, displayed on a monochromatic graphic LCD of $128 x 64$ pixels, the radar scan is performed in a $180^{\circ}$ rotation range making use of a servo motor for this task, a trace of the objects detected by the radar must be plotted on the screen, with typical application in mobile robotics.

KEYWORDS: Graphic LCD, Mobile Robotic, PSoC5LP, Servomotor, Ultrasound Sensor
\end{abstract}

Received: Nov 04, 2020; Accepted: Nov 24, 2020; Published: Dec 30, 2020; Paper Id.: IJMPERDDEC202068

\section{INTRODUCTION}

In applications for object detection, systems with infrared, acoustic or optical sensor technologies are generally used much more frequently. In many cases, these sensors tend to distort the signals that are emitted in environmental conditions such as rain, the presence of fog, darkness or different types of lighting.

Radar technology has the advantage of operating in any type of environmental condition. In practice, a radar system may be able to measure direction, height, distance, and/or speed from the echo reflected by both static and moving objects. Radar is an electronic system that can detect objects out of sight and determine the distance they are in by projecting radio waves onto them.

The word radar corresponds to the initials of "RAdio Detection And Ranging. [1]. The set of radar systems can be classified according to the type of emission signal: pulsed or continuous wave [2].

In general, for navigation applications of a mobile robot either autonomous or remotely operated must have an obstacle detection system [3], [4]. The function of these systems is to generate useful and reliable information for the navigation system. Among the technologies used in object detection for mobile robotics applications are mechanical, infrared, ultrasonic and laser systems. In general, the radar in robotics applications is used to assist the positioning of the robot by creating maps to avoid obstacles [5], [6]

\section{ANALYSIS AND MODELING}

\subsection{Ultrasound Sensor}

For the design and implementation of the radar was used the reference ultrasonic sensor HC-SR04 (Figure 1) has the characteristics presented in Table 1 [7]. 


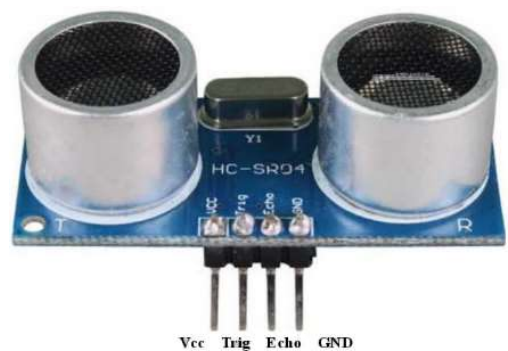

Figure 1: Ultrasonic sensor HC-SR04 [7]

Table 1: Specifications of the ultrasound sensor HC-SR04

\begin{tabular}{|c|c|}
\hline Parameter & Value \\
\hline Working Voltage & DC 5v \\
\hline Working Current & $15 \mathrm{~mA}$ \\
\hline Working Frequency & $40 \mathrm{~Hz}$ \\
\hline Max Range & $4 \mathrm{~m}$ \\
\hline Min Range & $2 \mathrm{~cm}$ \\
\hline Measuring Angle & $15^{\circ}$ \\
\hline Trigger Input Signal & 10 us TTL pulse \\
\hline Echo Output Signal & Input TTL lever signal and the range in \\
& proportion \\
\hline Dimension & $45 \times 20 \times 15 \mathrm{~mm}$ \\
\hline
\end{tabular}

This sensor is made up of 4 pins, which are Vcc, ground, trigger and echo, the way we should use this sensor to measure the distance is by sending a pulse to TRIGGER of $10 \mathrm{uS}$, after that he will be in charge of sending 8 sound cycles at $40 \mathrm{Khz}$ after the sound bounces it is received by the receiver and the sensor is in charge of generating a pulse signal with a high level of width proportional to the distance that the certain object is. The way this distance is calculated then is by calculating the time of this pulse in ECHO and it is done using (1).

$$
\text { Distance }=\frac{\text { Time up } * \text { Sound speed }}{2}
$$

It is divided into 2 because this time corresponds to the time the sound is emitted and then the time it bounces. Therefore, if we want to know the distance of an object in centimeters we should divide the time by 58 .

\subsection{SG90 Servo Motor}

The SG90 servo motor was used for the movement of the ultrasound radar, because of its ease of handling and even more importantly because of its low cost (Figure 2).

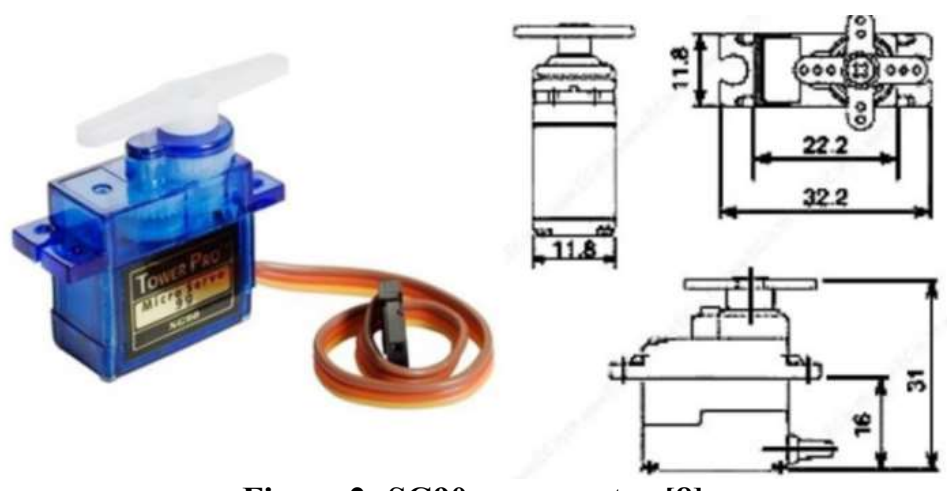

Figure 2: SG90 servo motor [8] 
Table 2 shows the basic specifications of the servo motor.

Table 2: SG90 Servomotor specifications

\begin{tabular}{|c|c|}
\hline Parameter & Value \\
\hline Weight & $9 \mathrm{~g}$ \\
\hline Dimension & $22.2 \times 11.8 \times 31 \mathrm{~mm}$ \\
\hline Stall torue & $1.8 \mathrm{kgf} * \mathrm{~cm}$ \\
\hline Operating Speed: & $0.1 \mathrm{~s} / 60$ degree \\
\hline Operating voltage & $4.8 \mathrm{~V}(\sim 5 \mathrm{v})$ \\
\hline Dead bandwidth & $10 \mathrm{us}$ \\
\hline Temperature range & $0^{\circ} \mathrm{C}-55^{\circ} \mathrm{C}$ \\
\hline
\end{tabular}

This servomotor has 3 pins one of them is VCC another is ground and another is the pin used to send a PWM that will indicate the position that the servo should have, the period of this PWM should be $20 \mathrm{~ms}$ and the position will depend on the high level that is in this signal, this time should be 1 to $2 \mathrm{~ms}$ approximately so that when it is in $1 \mathrm{~ms}$ he will be at $90^{\circ}$, when it is in $1.5 \mathrm{~ms}$ he will be at $0^{\circ}$ and when it is in $2 \mathrm{~ms}$ he will be at $-90^{\circ}$ (Figure 3 ). Note that these figures are approximate.

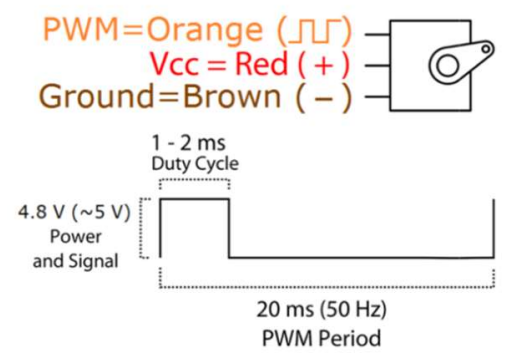

Figure 3: How to use the SG90 servo motor [8]

\subsection{Graphic LCD}

The graphic LCD 128x64 is an LCD that is divided into two 64x64 screens so it has two selectors that allow you to choose the screen to which you will send the respective commands, these selectors are called CS1 and CS2. It has another pin called $\mathrm{D} / \mathrm{I}$ which is used to indicate if it is a command or data that will be sent to the LCD, it has another one called R/W used to indicate if it is going to be read or written to. We also find the 8-bit bidirectional data bus where we will send the respective command or data, all this information can be seen in Table 3.

Table 3: Pin description [9]

\begin{tabular}{|c|c|c|c|}
\hline Pin No. & Symbol & $\begin{array}{l}\text { External } \\
\text { Connection }\end{array}$ & Function Description \\
\hline 1 & VDD & Power Supply & Power supply for logic (+5.0V) \\
\hline 2 & VSS & Power Supply & Ground \\
\hline 3 & vo & Adj.Power Supply & Power Supply for contrast (approx -3.5V) \\
\hline 4-11 & DB0-DB7 & MPU & Bi-directional 8-bit data bus \\
\hline 12 & CS1 & MPU & \multirow{2}{*}{$\begin{aligned} \text { Chip Selection: } & \text { CS1 }=\mathrm{H}, \mathrm{CS} 2=\mathrm{L} \text { : select IC1 (left side) } \\
& \mathrm{CS} 1=\mathrm{L}, \mathrm{CS} 2=\mathrm{H} \text { : select IC2 (right side) }\end{aligned}$} \\
\hline 13 & $\operatorname{CS2}$ & MPU & \\
\hline 14 & RST & MPU & Active Reset Signal \\
\hline 15 & $\mathrm{R} / \mathrm{W}$ & MPU & Read/Write select signal. $R / W=1$ : Read $R / W$; $=0$ : Write \\
\hline 16 & $\mathrm{D} / 1$ & MPU & Register select: $1=$ Data, $0=$ Instruction \\
\hline 17 & $E$ & MPU & Operation enable signal. Falling edge triggered. \\
\hline 18 & VEE & Power Supply & Negative voltage output (-10V) \\
\hline 19 & LED+ & Power Supply & Power for LED Backlight ( $+3.5 \mathrm{~V})$ \\
\hline 20 & LED- & Power Supply & Ground for Backlight \\
\hline
\end{tabular}


The commands used for the correct operation of the graphic LCD are presented in Table 4 below.

Table 4: Commands of the Graphical LCD [9]

\begin{tabular}{|c|c|c|c|c|c|c|c|c|c|c|c|}
\hline Instruction & RS & $\mathbf{R} / \mathbf{W}$ & DB7 & DB6 & DB5 & DB4 & DB3 & DB2 & DB 1 & DBO & Function \\
\hline Display on/off & L & L & L & L & H & $\mathrm{H}$ & $\mathrm{H}$ & $\mathrm{H}$ & $\mathrm{H}$ & LH & $\begin{array}{l}\text { Controls the display on or off. } \\
\text { Internal status and display RAM } \\
\text { data is not affected. } \\
\text { L:OFF, H:ON }\end{array}$ \\
\hline $\begin{array}{l}\text { Set address } \\
\text { (Y address) }\end{array}$ & L. & L & L & H & \multicolumn{6}{|c|}{ Yaddress $(0-63)$} & $\begin{array}{l}\text { Sets the } Y \text { address in the } Y \\
\text { address counter. }\end{array}$ \\
\hline $\begin{array}{l}\text { Set page } \\
\text { (X address) }\end{array}$ & L & L & H & L & $\mathrm{H}$ & $\mathrm{H}$ & H & \multicolumn{3}{|c|}{ Page (0-7) } & $\begin{array}{l}\text { Seis the } X \text { address at the } X \\
\text { address register. }\end{array}$ \\
\hline $\begin{array}{l}\text { Display } \\
\text { Start line } \\
\text { (Z address) }\end{array}$ & L & L & $\mathrm{H}$ & H & \multicolumn{6}{|c|}{ Display start ine (0-63) } & $\begin{array}{l}\text { Indicates the display data } \\
\text { RAM cisplayed at the top of the } \\
\text { screen. }\end{array}$ \\
\hline Status read & L & $\mathrm{H}$ & Busy & 1 & $\begin{array}{l}\text { On } \\
\text { Off }\end{array}$ & Reset & L & L & L & L & \begin{tabular}{|l} 
Read status. \\
BUSY L: Ready \\
H: In operation \\
ONJOFF L: Display ON \\
H: Display OFF \\
RESET L: Normal \\
H: Reset
\end{tabular} \\
\hline $\begin{array}{l}\text { Write display } \\
\text { data }\end{array}$ & $\mathrm{H}$ & L & \multicolumn{8}{|c|}{ Write data } & $\begin{array}{l}\text { Writes data (DBO: } 7 \text { ) into display } \\
\text { data RAM. After writing } \\
\text { instruction, } Y \text { address is } \\
\text { increased by } 1 \text { automatically. }\end{array}$ \\
\hline $\begin{array}{l}\text { Read display } \\
\text { data }\end{array}$ & $\mathrm{H}$ & $\mathrm{H}$ & \multicolumn{8}{|c|}{ Read data } & $\begin{array}{l}\text { Reads data (DBO: } 7 \text { ) from display } \\
\text { data RAM to the data bus. }\end{array}$ \\
\hline
\end{tabular}

The memory structure of this graphic module is grouped in bytes in a vertical direction, divided into pages. The least significant bit of the first byte of memory of the first controller corresponds to the point located on the screen at the top left, and the most significant bit of the last byte of memory of the second controller corresponds to the point located on the screen at the bottom right.

\section{ULTRASONIC RADAR DESIGN}

\subsection{Modeling}

To display the elements found with the sensor in the graphic LCD we must find a position using rectangular coordinates that will indicate in which pixel we should write (Figure 4), and for this, we must take into account that thanks to the PWM that we must send to the servo, we have a position of the servo and it depends on the angle at which the ultrasonic sensor is making the reading, ie if we take that data we can convert it to an angle, the distance corresponds to the reading obtained with the help of the sensor HC-SR04. Then we have polar coordinates and we must convert them to rectangular coordinates.

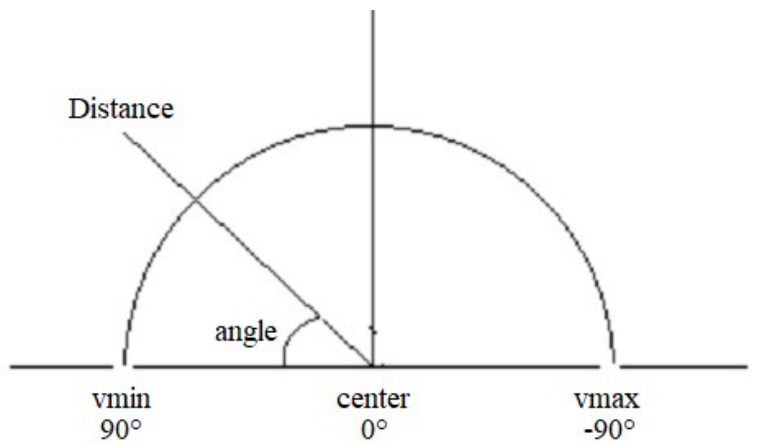

Figure 4: Displaying what we want to see with the graphic LCD 
Taking into account this, we proceed to find the necessary equations for the visualization, for this, we must determine a center, which will be the average of the two maximum and minimum values used for the movement of the servomotor. This is then as seen in (2).

$$
\text { center }=\frac{v \min +\text { vmax }}{2}
$$

As with the graphic LCD, we cannot place "negative positions" we will work with the magnitude of the difference between the center and the position of the servo, if the difference is the maximum that is in vmin or vmax we will know that the corresponding angle is $90^{\circ}$ or $-90^{\circ}(\pi / 2$ or $-\pi / 2)$. Then we have (3).

$$
\text { dif }=\mid \text { position }- \text { center } \mid
$$

And the maximum difference would be determined by (4).

$$
\text { difm }=\frac{v m a x-v m i n}{2}
$$

Applying a rule of three to find the corresponding angle depending on the position of the servo motor we have (5).

$$
\text { angle }=\operatorname{dif} * \frac{\pi}{2 * \text { difm }}
$$

Remember that the maximum difference corresponds to the value of $\pi / 2$. The distance will be found by reading the ultrasonic sensor. That way we only have to find $\mathrm{x}$ and $\mathrm{y}$ applying trigonometric properties, we have then (6).

$$
x=\text { distance } * \cos (\text { angle }) \quad \mathrm{y}=\text { distance } * \cos (\text { angle })
$$

I would only subtract the location of the respective point and give it a "positive or negative" value depending on whether the center is greater or less than that point. The center will be located in the middle of the LCD.

\subsection{Radar Design in PSoC Creator}

The first thing we must do is determine the objects needed for the development of the radar. Based on that, the block diagram of Figure 5 is proposed.

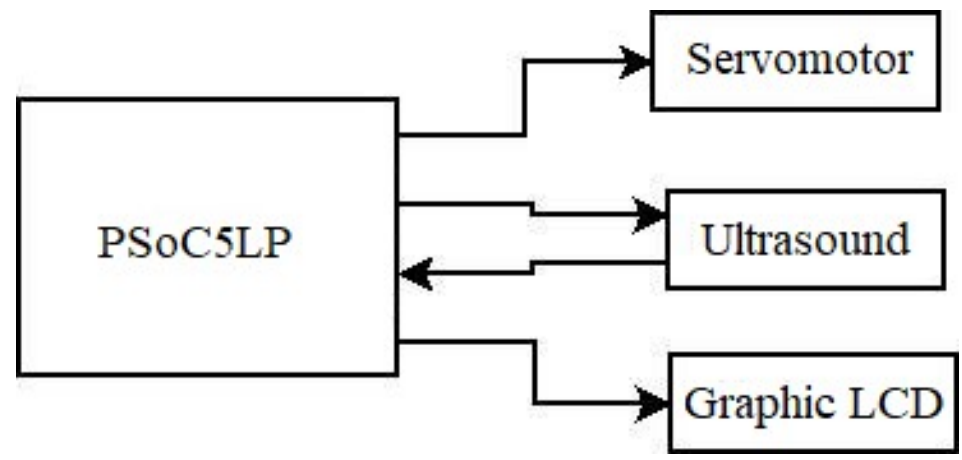

Figure 5: Block diagram of the elements used for ultrasonic radar

Given how all elements have interconnected the configuration of the PSoC5LP [10], [11] that was made is shown in Figure 6. 


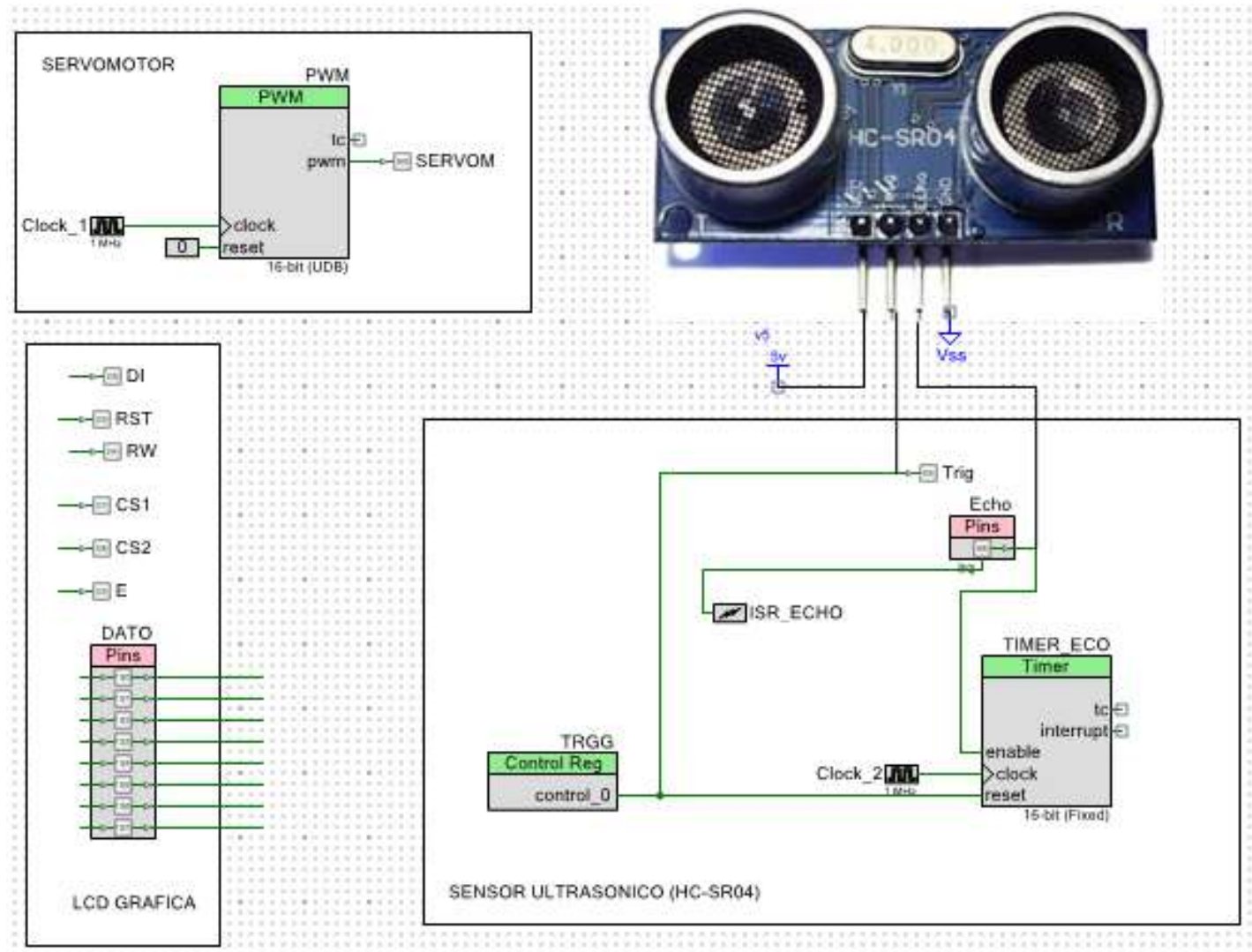

Figure 6: Configuration used in the PSoC5LP

\subsection{Servomotor Operation}

For the operation of the servo motor was used a PWM (Figure 7), so that it was configured to have a period of $20 \mathrm{~ms}$, it was necessary a clock of $1 \mathrm{Mhz}$, and through software was placed the comparison value, taking into account that the period that was placed in the PWM [10], [11] is 20000 the comparison value would then be between 1000 and 2000, but testing this PWM determined that to give a path of approximately $180^{\circ}$ the comparison value should be between 480 and 2270. This value was set by software.

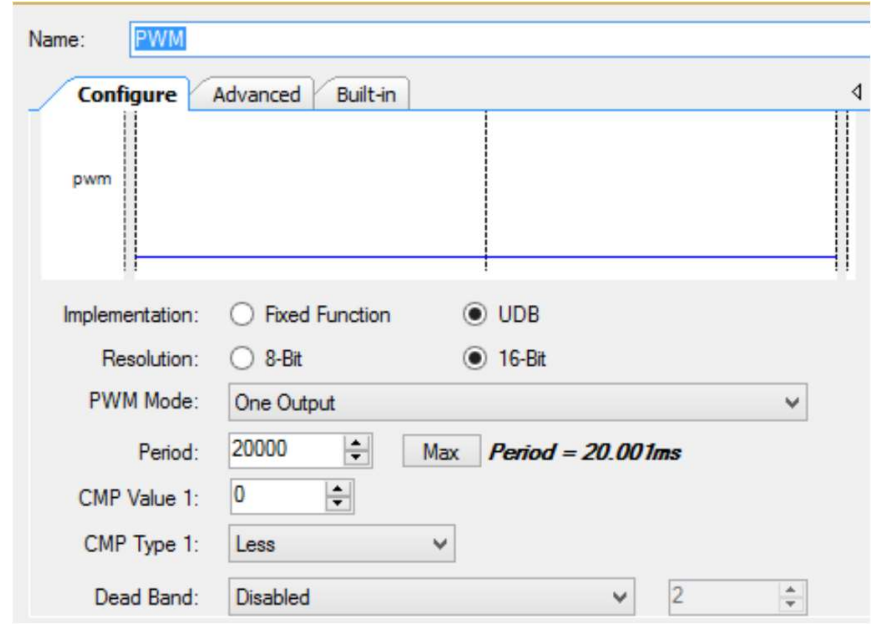

Figure 7: PWM Configuration 


\subsection{Operation of the Ultrasonic Sensor HC-SR04}

To operate the ultrasound sensor was used 2 digital pins which were configured by Hardware Connection, one of them for the Trigger was set to Strong Drive mode and used a control register which in turn served to reset the Timer [10], [11] that counted the duration of the pulse produced in ECHO pin. The ECHO pin was configured as high digital impedance and added a leading-edge interruption because at the time that the pulse received from echo ends, the time we would have in the Timer is the time with which we can calculate the distance. The timer handling a $1 \mathrm{MHz}$ clock was configured according to what is presented in Figure 8.

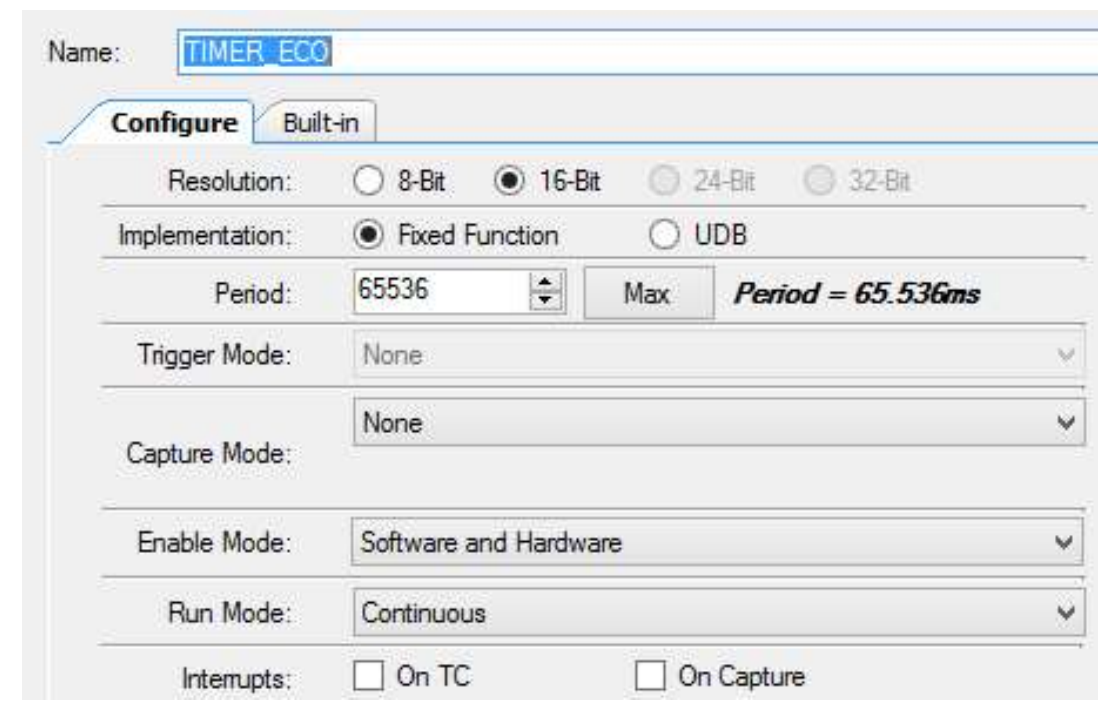

Figure 8: Configuration of the Timer used

The Enable of the timer corresponded to the ECHO that is to say that when the pulse started, it began to count and stopped when echo returned to zero, if we needed to find a distance and with it a new time we had to reset the counter and for it, we used the same trigger pulse to restart it before it began to count.

In software, we did what is shown in the ultrasonic radar design section, to create sine and cosine tables that depended on the servo motor position, using Matlab using the code shown in Figure 9.

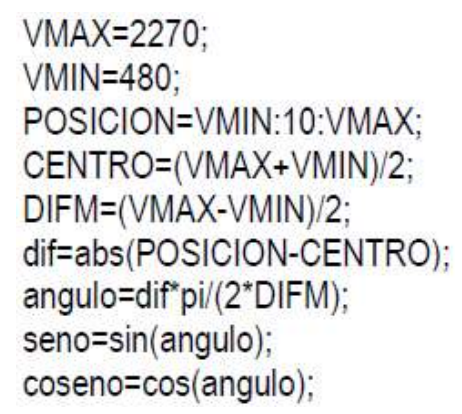

\section{Figure 9: Matlab Code}

These tables were copied and used to calculate $\mathrm{x}$ and $\mathrm{y}$ using a function with the name of calculusxy() where it is important once we have read the ultrasound sensor and had the position of the servomotor. The way the PSoC5LP was programmed is determined by the flowchart presented in Figure 10. 


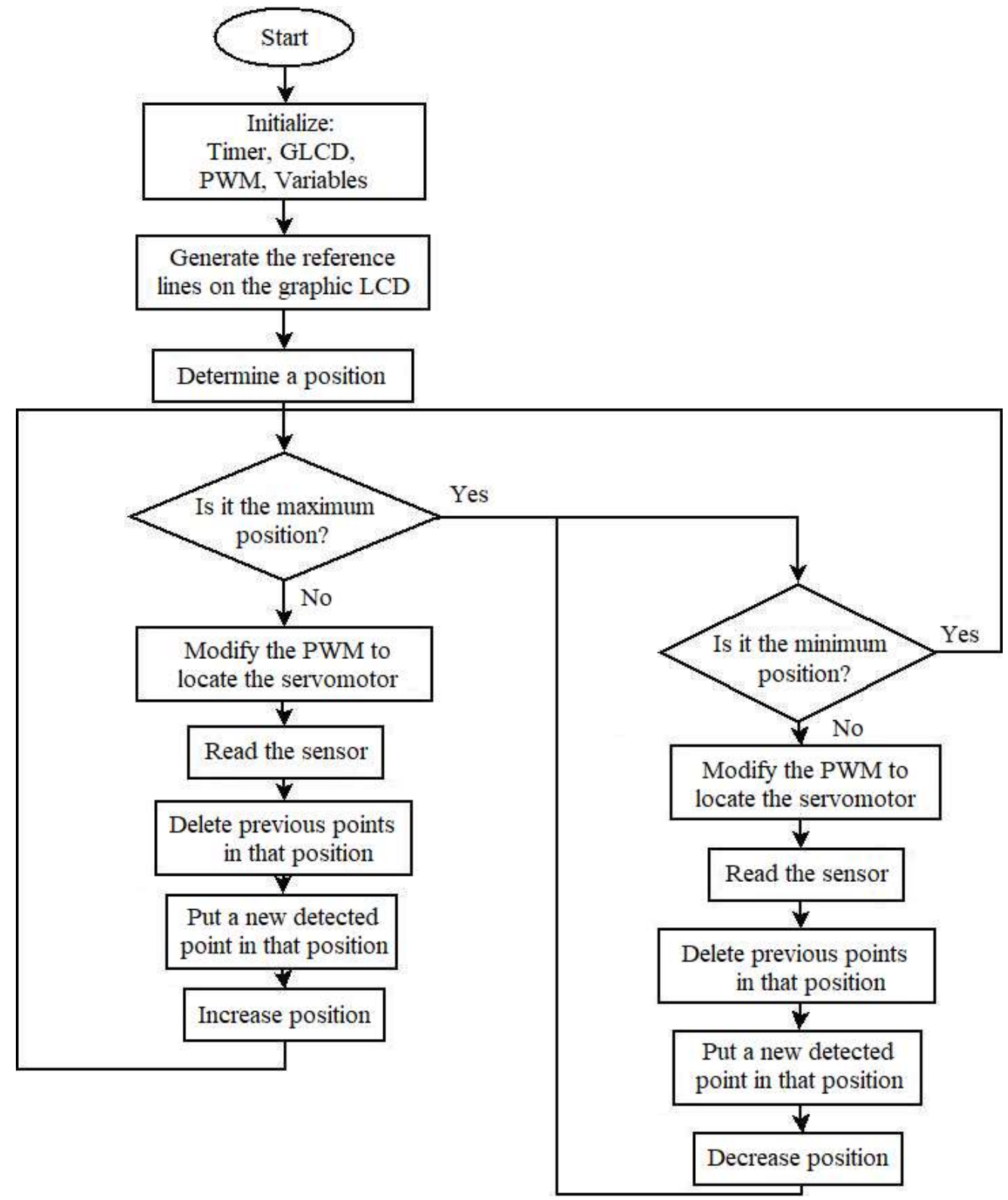

Figure 10: General flowchart

\section{RESULTS}

Problems were reading the graphic LCD because there were points that had nothing to do with the ultrasound sensor reading, the solution was to create a buffer and there store the data from the graphic LCD, the functions used to display in the GLCD did not generate any problem.

To calculate the points to be created and thus visualize what was read from the ultrasonic sensor was used at first the MATH.H library, but using this library the program ran too slow, the solution was to create tables of the sine and cosine values depending on the position of the servo, so the PSoC5LP did not have to calculate so many things and instead should only read the data from a table.

For the $180^{\circ}$ reading at first, only 19 readings were made, but the points were too far apart so it was not understood what you were reading, the solution was to create more points 180 readings for the $180^{\circ}$, ie for each degree made a reading. 
Figure 11 shows the final result of the radar implemented with the PSoC5LP

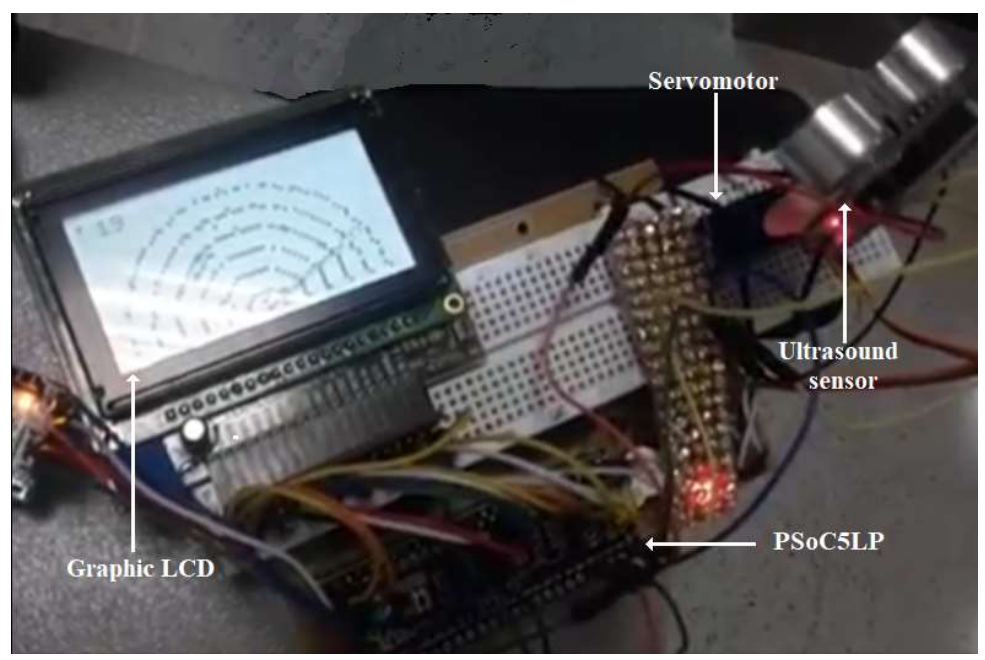

Figure 11: Radar implemented with the PSoC5LP

\section{CONCLUSIONS}

The PSoC5LP is an embedded system that meets the high expectations of its users and at a very low cost, offers a friendly interface and easy to use to develop multiple jobs.

The handling of functions in the code facilitates programming and allows a better understanding of the code, so that, when you need a procedure more than once, you would not have to write it every time, it is only to create a function and each time you need that procedure call it.

At the time of creating the code is very unlikely not to make mistakes, therefore, the Debug in real-time offered by PSoC Creator is very useful, when looking for the causes of an error that is not easily found, making the instructions step by step.

The type of data used for some variables is important, to avoid loss of information are required large data types, or the case of handling negative numbers should be used data type that allows this.

\section{ACKNOWLEDGMENTS}

The authors would like to thank the Universidad Distrital Francisco José de Caldas and the LASER research group that supported the development and testing of the project.

\section{REFERENCES}

1. Escuela Técnica IPEM 56 Abraham Jiménez. (2008). Radar metereológico. Retrieved from: http://www.oni.escuelas.edu.ar/2008/CORDOBA/1324/trabajo/radarmeteorologico.html

2. González, Daniel Vargas. (2014). Detección de movimiento mediante técnicas radar CW-FM en banda W. Barcelona. Universitat Politècnica de Catalunya, 2014.

3. Vivet, D., Checchin, P. \& Chapuis, R. (2013). Localization and Mapping Using Only a Rotating FMCW Radar Sensor. Sensors. 13:4527-4552.

4. Muñoz, P. A., Imbachí, S. C. \& Flórez, J. F. (2017) Obstacle detection system with Scanner. Ingeniería y desarrollo. 32(2):200217. 
5. Barreto, A. M. (2017). Implementación de un Sistema Radar Móvil Usando un Sensor Doppler para la Detección de Obstáculos. Universidad de Los Llanos. Facultad de Ciencias Básicas e Ingeniería. Escuela de Ingenierías. Programa de Ingeniería Electrónica. Villavicencio. Colombia. 2017.

6. Wicks, M. (2003). Radar the next generation - sensors as robots. 2003 Proceedings of the International Conference on Radar (IEEE Cat. No.03EX695), Adelaide, SA, Australia, 2003, pp. 8-14.

7. Elecfreaks. (2019). Ultrasonic Ranging Module HC - SR04. Retrieved from: https://cdn.sparkfun.com/datasheets/Sensors/Proximity/HCSR04.pdf

8. Electrónicos Caldas. (2019). SG909 g Micro Servo. Retrieved from: https://www.electronicoscaldas.com/datasheet/SG90_Tower-Pro.pdf

9. Micros y más micros. (2007). Terminal para GLCD-USB (controlador Ks018). Retrieved from: https://micros.mforos.com/1149907/6882056-terminal-para-glcd-usb-controlador-ks0108-v1-0/

10. Camargo, J. \& Perdomo, C. (2016). Introducción al PSoC5LP: Teoría y aplicaciones prácticas. First ed., Bogotá: Ed. Universidad Distrital, 2016.

11. Camargo, J., Perdomo, C. \& Bermúdez, B. (2019). Proyectos prácticos con PSoC5LP. First ed., Bogotá: Ediciones de la U, 2019. 